\title{
O paradoxo da ideologia
}

\section{The paradox of ideology}

- JUREMTR MACHA DO DA SILVA a

Pontifícia Universidade Católica do Rio Grande do Sul, Programa de Pós-Graduação em

Comunicação Social. Porto Alegre - RS, Brasil

\section{RESUMO}

a Professor titular da Pontifícia

Este texto examina definições de ideologia de autores clássicos e um paradoxo: se tudo é ideológico e se ideologia tudo condiciona, como é possível compreender o seu funcionamento e fazer a sua negação?

Palavras-chave: Ideologia, imaginário, cultura, ciência social

\section{ABSTRACT}

This text examines definitions of ideology by classic authors and a paradox: if everything is ideological and if ideology conditions everything, how is it possible to understand its functioning and make its denial?

Keywords: Ideology, imaginary, culture, social sciences 
O mais moderno é também o mais arcaico. (Debord, 1987, p. 20)

${ }^{1}$ No original: "L'Idéologie est une partie de la Zoologie, et c'est sur-tout dans l'homme que cette partie est importante et mérite dêtre approfondie: aussi léloquent interprète de la nature, Buffon, aurait-il cru n’avoir pas achevé son histoire de l'homme, s'il n'avait pas au moins essayé de décrire sa faculté de penser". Traduzido por Nuno Melim da terceira edição (1817), disponível em: https://bit.ly/3ho4AHy.

\section{O QUE É IDEOLOGIA?}

A história do termo ideologia começa, segundo a tradição do termo, com Destutt de Tracy, que, após ter sido preso durante a Revolução Francesa e solto em 1794, criou o termo em 1796 para designar uma ciência das ideias. Com isso, ele teve problemas com Napoleão, que o rotularia pejorativamente de "ideólogo", mas ressurgiu para o mundo dos intelectuais e publicou, em 1815, o último dos quatro volumes de Elementos de Ideologia. Ele tinha concepção original da matéria com a qual estava lidando, como se vê no prefácio da primeira edição da sua volumosa obra:

A Ideologia é uma parte da Zoologia e é sobretudo no homem que essa parte é importante e merece ser aprofundada. De tal maneira que Buffon, eloquente intérprete da natureza, acreditou que não acabaria a sua história do homem sem pelo menos tentar descrever a sua faculdade de pensar ${ }^{1}$. (de Tracy, 1804/2013, p. 3)

Grande projeto.

Não se tem notícia por enquanto de animal agindo por ideologia. Pode-se, contudo, definir o homem como um animal ideológico. Destutt de Tracy queria ser descritivo. Não era humorista nem estava antecipando as lutas animalescas em torno da palavra ideologia, que se tornaria autoelogio e insulto. Quando alguém diz "a minha ideologia", orgulha-se do que pensa; quando se trata da ideologia do outro, tudo muda de figura. O elogio vira ataque, ofensa, desqualificação. No extremo, ideologia é o pensamento do outro, esse ignorante submetido às ideias que defende sem perceber o quanto elas o escravizam e condenam. A ideologia, como entidade dogmática e poderosa, não fala. Faz falar. Não silencia. Cala. Não liberta, aprisiona. Não ilumina. Obscurece.

Marx e Engels, em A Ideologia Alemã (1846/1998), teriam outras ambições e dariam um salto epistemológico que não mais seria desconsiderado por seus seguidores nem por seus oponentes:

A produção de ideias, de representações e da consciência está em primeiro lugar direta e intimamente ligada à atividade material e ao comércio material dos homens; é a linguagem da vida real. As representações, o pensamento, o comércio intelectual dos homens surge aqui como emanação direta do seu comportamento material. $\mathrm{O}$ mesmo acontece com a produção intelectual quando esta se apresenta na linguagem das leis, política, moral, religião, metafísica, etc., de um povo. São os homens 
que produzem as suas representações, as suas ideias, etc., mas os homens reais, atuantes e tais como foram condicionados por um determinado desenvolvimento das suas forças produtivas e do modo de relações que lhe corresponde, incluindo até as formas mais amplas que estas possam tomar. A consciência nunca pode ser mais do que o ser consciente e o ser dos homens é o seu processo da vida real. E se em toda a ideologia os homens e as suas relações nos surgem invertidos, tal como acontece numa câmera obscura, isto é apenas o resultado do seu processo de vida histórico, do mesmo modo que a imagem invertida dos objetos que se forma na retina é uma consequência do seu processo de vida diretamente físico. (p. 18)

A ideologia seria uma engrenagem, um dispositivo de regulação das consciências, uma ferramenta de conquista dos corações e mentes. Se, porém, o homem age condicionado por seu contexto material, submetido às limitações do seu tempo e do modo de produção dominante, como imaginar uma revolução total, uma inversão como aquela que teria colocado a própria leitura da história, antes de cabeça para baixo, sobre seus pés, destacando, por exemplo, que o homem criou Deus e não o oposto?

Os pensamentos da classe dominante são também, em todas as épocas, os pensamentos dominantes; em outras palavras, a classe que tem o poder material dominante numa determinada sociedade e também o poder espiritual dominante. A classe que dispõe dos meios da produção material dispõe também dos meios da produção intelectual, de tal modo que o pensamento daqueles aos quais são negados os meios de produção intelectual está submetido também à classe dominante. (Marx \& Engels, 1846/1998, p. 49)

Se a classe dominante tudo domina, inclusive ou principalmente a mente dos dominados, como eles podem ter consciência dessa dominação? Onde está a brecha? Onde se encontra o ponto de ruptura? Onde o sistema falha? Os discípulos de Marx tentariam tornar essa dimensão mais operacional, palpável, concreta, perceptível a olho nu. Althusser (1980) propõe duas teses complementares sobre a ideologia: 1) "A ideologia representa a relação imaginária dos indivíduos com as suas condições reais de existência" (p. 77); 2) "A ideologia tem existência material” (p. 83). A difusão da ideologia na sua materialidade teria os seus aparelhos ideológicos de estado (AIE) como dispositivos:

O AIE religioso (o sistema das diferentes igrejas);

O AIE escolar (o sistema das diferentes escolas públicas e particulares);

O AIE familiar; 
O AIE jurídico;

O AIE político (o sistema político com os diferentes partidos);

O AIE da informação (imprensa, rádio, televisão, etc.);

O AIE cultural (letras, belas artes, desportos, etc.). (p. 46)

Para Althusser não há muitas brechas. Ou não há brecha alguma: tudo é ideologia. Basta reler a lista dos aparelhos ideológicos para se chegar à acachapante conclusão de que "está tudo dominado". O indivíduo é submetido 24 horas por dia à implacável contaminação ideológica: em casa, na igreja, na escola, no trabalho, no lazer, no teatro, no cinema, no jogo de futebol, onde quer que esteja. Nada se faz sem estar sob influência ideológica:

As práticas sociais e as ideias que os homens fazem delas estão estreitamente relacionadas. Pode dizer-se que não há prática sem ideologia e que qualquer prática, incluindo a científica, se realiza através de uma ideologia. Em todas as práticas sociais (quer pertençam ao domínio da produção económica, ao da ciência, ao da arte, ao do direito, ao da moral ou da política), os homens que atuam estão submetidos às ideologias correspondentes, independentemente da sua vontade e mais ou menos com uma total ignorância do assunto. (Althusser, 1989, p. 49)

Se até a prática científica é ideológica e se os homens agem em "mais ou menos total ignorância do assunto", como pode se dar um desvelamento da ideologia ou uma denúncia do seu poder? A única brecha é o mais ou menos dessa frase sobre a ignorância da dominação ideológica. Estaria aí o ponto de fuga? Essa leitura é diferente daquela encontrada numa das acepções levantadas por Stoppino (1986), como "sentido fraco", no inventário sustentado por Norberto Bobbio de sentidos forte e fraco de ideologia: "Um conjunto de ideias e de valores respeitantes à ordem pública e tendo como função orientar os comportamentos políticos coletivos" (p. 585).

Quem orientaria? Quem definiria a ordem pública? Esses termos aparentemente neutros exigem um conteúdo que só pode resultar das disputas entre atores sociais ideologicamente distintos. Entra-se num círculo vicioso: toda definição de ideologia só pode ser ideológica. Se ideologia é encobrimento da realidade, então as definições marxistas de ideologia também encobrem ou distorcem alguma coisa? Como pode ideologia significar uma distorção e existir um olhar ideológico sem distorção, que não encobre, mas descobre, revela, ilumina e esclarece?

Impasse? Contradição insuperável? Paradoxo? Limite conceitual da linguagem? Ou ideologia como encobrimento é sempre a visão de mundo do outro, 
enquanto a boa ideologia - a minha, a nossa - é corpo de ideias, doutrina, conjunto orientador de valores? Evidentemente a concepção de Althusser é mais aparentada da interpretação que seria adotada no século XXI pelo esloveno Zizek (1996):

Ideologia pode designar qualquer coisa, desde uma atitude contemplativa que desconhece sua dependência em relação à realidade social, até um conjunto de crenças voltado para a ação; desde o meio essencial em que os indivíduos vivenciam suas relações com uma estrutura social até as ideias falsas que legitimam um poder político dominante. (p. 9)

Vários problemas epistemológicos aparecem: se o termo ideologia pode designar qualquer coisa, isto e aquilo, tudo e o contrário, ainda tem valor conceitual? Se ideologia pode ser ignorância da dependência, valores para a ação, crença e ideia falsa, algum sujeito enunciador vê a sua ideologia como crença ou ideia falsa? Ou só é falsa a ideia do outro, do oponente, daquele que deve ser informado, emancipado, iluminado? Existem critérios objetivos de elucidação do verdadeiro e do falso em ideologia ou toda ideologia ilude o ideologizado? Se existe critério objetivo, então, deve-se concluir que nem tudo é ideológico. Nesse sentido, boa parte das teses desabaria.

Cada época e cada autor produzem a definição de ideologia de que necessitam. Ou geram aquilo que deles exige o contexto material? Qual o grau, mesmo relativo, de autonomia do indivíduo? O conceito de classe social sofre constantes atualizações. A oposição entre detentor dos meios de produção e vendedor da força de trabalho não parece mais sob medida para enquadrar todos os tipos possíveis do mundo da produção. Kellner (2001) calibrou a sua conceituação para novas causas:

A ideologia pressupõe que "eu" sou a norma, que todos são como eu, que qualquer coisa diferente ou outra não é normal. Para a ideologia, porém, o "eu”, a posição da qual a ideologia fala, é (geralmente) a do branco masculino, ocidental, de classe média ou superior; são posições que veem raças, classes, grupos e sexos diferentes dos seus como secundários, derivativos, inferiores e subservientes. A ideologia, portanto, diferencia e separa grupos em dominantes/dominados e superiores/ inferiores, produzindo hierarquias e classificações que servem aos interesses das forças e das elites do poder. (p. 83)

Caso se aceitem as definições de Kellner, por hipótese, deve-se concluir que só há ideologia onde o macho branco ocidental atua? Sem negar a dominação 
masculina branca ocidental, aparentemente nítida, deve-se imaginar a possibilidade de relações sociais sem ideologia? Ou a ideologia é um sistema de hierarquia social intrínseco a qualquer agrupamento humano? Se há ideologias, há ideólogos. Quem são eles? Como são produzidos? Como se reproduzem? Gramsci (1979) tinha uma ideia:

Cada grupo social, nascendo no terreno originário de uma função essencial no mundo da produção econômica, cria para si, ao mesmo tempo, de um modo orgânico, uma ou mais camadas de intelectuais que lhe dão homogeneidade e consciência da própria função, não apenas no campo econômico, mas também no social e no político ... A escola é o instrumento para elaborar os intelectuais de diversos níveis. A complexidade da função intelectual nos vários Estados pode ser objetivamente medida pela quantidade das escolas especializadas e pela sua hierarquização. (p. 3)

Outra vez, surgem questionamentos: se a escola é AIE, como queria Althusser, e se forma intelectuais orgânicos para o poder dominante, como dizia Gramsci, ou seja, se reproduz o sistema de hierarquia social dominante, como sugerem Bourdieu e Passeron (1982), como pode ser também emancipadora? A escola só reproduz? Só emancipa? Ou reproduz e emancipa? Como pode um mesmo professor emancipar alguns alunos com a formação que dá e manter outros na ignorância pelo encobrimento ideológico da realidade? Outro impasse: se a educação é fundamental para a mudança, mas a escola é reprodutora, como contar com ela para a transformação? Ou a escola só será emancipadora depois que a emancipação já tiver acontecido?

O tempo da escola como aparelho ideológico principal atingiu o seu limite. A imprensa, hoje chamada de mídia, já era para Gramsci (1979) outro dispositivo importante a ser utilizado para moldar pessoas:

Os leitores devem ser considerados a partir de dois pontos de vista principais: 1) como elementos ideológicos, "transformáveis" filosoficamente, capazes, dúcteis, maleáveis à transformação; 2) como elementos "econômicos", capazes de adquirir as publicações e de fazê-las adquirir por outros. (p. 163)

O leitor funcionaria como um transmissor, um segundo nível da cadeia de disseminação. O mesmo valeria, depois de Gramsci, para os telespectadores. Há, porém, na perspectiva de Gramsci um valor potencialmente positivo: esse leitor do qual está falando seria transformável para a emancipação. Dominado ideologicamente por ser dúctil, poderia ser libertado ideologicamente por ser 
maleável, apto a uma nova inscrição? Não seria isso uma nova submissão ou dominação? Na base da ideologia está a compreensão de que a repressão não basta para controlar os dominados. Chomsky (2007) explica com certa clareza:

Para dominar, a violência não basta. É preciso uma justificativa de outra natureza. Assim, quando uma pessoa exerce poder sobre outra, seja um ditador, um colonizador, um burocrata, um patrão ou um marido, ele precisa de uma ideologia justificadora, que sempre redunda na mesma coisa: a dominação é exercida para "o bem" do dominado. Em outras palavras, o poder se apresenta sempre como altruísta, desinteressado, generoso. (para. 16)

Eis tudo: a ideologia disfarça e justifica a dominação. Nesse caso, ela é negativa. Já a ideologia como conjunto de valores para a ação seria positiva. Cabe ao enunciador indicar o sentido de ideologia que está usando e ao interlocutor perceber qual a acepção em jogo. Essa ambivalência serve a quem? Num sentido, é distorção da realidade para encobrir a dominação; no outro, visão de mundo legítima e orgulhosa. O problema é que, em geral, quando o enunciador pensa estar falando da sua legítima visão de mundo, o receptor pode estar pensando em encobrimento da realidade. O mesmo se dá, de modo invertido, quando o enunciador ataca a visão de mundo do outro como falsa ideia e este se defende com a sua ideologia como visão de mundo contra a distorção do outro. Em outras palavras, há quase sempre desencontro conceitual.

\section{IDEOLOGIA COMO ENCOBRIMENTO}

Conceitos têm história. Ao longo do tempo, bifurcam-se, crescem, minguam; ou um sentido toma a dianteira e, mesmo constantemente remetido às origens para alguma correção, triunfa sobre os demais. Marx e Engels (1846/1998) enraizaram a ideia de falsa consciência:

Até agora, os homens sempre tiveram ideias falsas a respeito de si mesmos, daquilo que são ou deveriam ser. Organizaram suas relações em função das representações que faziam de Deus, do homem normal etc. Esses produtos de seu cérebro cresceram a ponto de dominá-los completamente. Criadores, inclinaram-se diante de suas próprias criações. Livremo-los, pois, das quimeras, das ideias, dos dogmas, dos seres imaginários, sob o jugo dos quais eles se estiolam. Revoltemo-nos contra o domínio dessas ideias. Ensinemos os homens a trocar essas ilusões por pensamentos correspondentes à essência do homem, diz alguém; a ter para com elas uma atitude crítica, diz outro; a tirá-las da cabeça, diz o terceiro, e a realidade atual desmoronará. (p. 26) 
A ideologia encobre, falsifica, distorce, inverte, naturaliza o construído historicamente, legitima a dominação, faz o dominado ver na sua dominação um estado normal e indiscutível, tranquiliza o dominante, diminui a necessidade de repressão, convence, submete, subordina, conquista a submissão voluntária do enganado, ilude. Funciona como um ato de comunicação de mão única: o iludido recebe pronta uma visão de mundo sem poder, em princípio, a ela responder, pois os indivíduos ignoram a situação ideológica na qual se encontram dominados.

O que permitiu que Engels e Marx compreendessem essa dinâmica? Por que o empresário Engels e o autônomo Marx conseguiram fugir da limitação ideológica a que estavam, como todos, submetidos e desvelar o funcionamento da engrenagem? Teria Engels, o patrão, contado a Marx como funcionava a sua classe e como se fazia para iludir os dominados? Não se trata aqui de desqualificar Marx e Engels ou de fazer um discurso antimarxista rasteiro. Eles revelaram aspectos pertinentes da dominação ideológica. A questão é: como puderam chegar a tanto? Como escaparam à influência das criaturas que dominavam os cérebros dos seus contemporâneos? Por que os demais patrões não tiveram a mesma iluminação de Engels na medida em que detinham informações equivalentes? Ou a experiência de Engels foi inseminada pelo encontro com Marx? As biografias explicam o ocorrido mais do que o material?

$\mathrm{O}$ mágico faz o truque. A maioria não compreende o funcionamento dessa ilusão individual ou coletiva. Marx e Engels desvendaram o truque ideológico do capitalismo. Não perceberam, contudo, que também eles poderiam fazer truques? O marxismo é uma anti-ideologia ou uma ideologia que desvenda as demais e não se vê como ideologia no sentido de encobrimento? É uma metaideologia? Uma ideologia sem ideologia? Essas questões encontram sentido na medida em que os marxistas - as esquerdas, em geral - são constantemente acusados "de ideologia" como incapacidade de perceber a realidade, suposta ou não, em função de uma matriz mental, uma lente que os levaria, voluntariamente ou não, a preferir a concepção idealizada aos fatos, a tese ao empírico.

Fica implícito no texto de Marx e Engels (1846/1998) que é possível extirpar da cabeça de alguém as criaturas que a povoam e deturpam a sua visão de mundo. A isso se chama costumeiramente de crítica. Essa crítica é uma aliança entre informação, observação, experiência e análise. Se isso é possível, Althusser $(1980,1989)$ equivoca-se: uma análise capaz de compreender e desvendar a própria ideologia não pode ser ideológica. Talvez pudesse ser chamada de científica ou de pós-ideológica. Em contrário, há um contrassenso, um defeito de raciocínio: se a ideologia é denunciada como distorção, compreendê-la não pode ser outra distorção. Só pode ser um desvelamento. Logo, não pode ser 
um novo encobrimento. Ou ninguém tem a capacidade de denunciar a própria ideologia? Só se pode ser decifrado por outro? O mágico conhece o truque que faz. O iludido não pode por conta própria estudá-lo até compreender como se dá a ilusão?

De toda maneira, aquele que decifra não se ilude. Em caso de ilusão, não há desvendamento. Não se revela o truque com outro truque, salvo se tudo for truque. Mas se tudo é truque, como saber o que é truque? Quando tudo é truque, por suposição, ainda há truque? Se todos estamos iludidos, que sentido faz falar em ilusão e como alguém pode saber que se trata de ilusão? Há uma visão não iludida no olhar iludido? Uma elite esclarecida? Por quem? Fora de todos os aparelhos ideológicos? Entramos no terreno da lógica. Por consequência, a decifração, se for de fato decifração, não pode ser outra ideologia.

Resta um aspecto a examinar, talvez uma hipótese, enfim, um ponto nebuloso: e se o que permite o desvelamento da ideologia for algo absolutamente individual, uma faculdade do sujeito pensante? E se o conhecimento daquilo que é conformado pelas condições materiais de existência exigir para ser compreendido um fator intangível - metafísico? -, um componente que não se escolhe e não se compra, dependendo de uma espécie de loteria existencial. Qual seria?

\section{CATEGORIA DE ACUSAÇÃO E ANTÍDOTO}

Os conceitos sofrem mutações. Atualmente ideologia é, sobretudo, uma categoria de acusação. Indica que o oponente distorce consciente ou inconscientemente uma realidade passível de ser provada enquanto tal. Para Althusser (1980) "1. Só existe prática através e sob uma ideologia; 2. Só existe ideologia através do sujeito e para sujeitos" (p. 91). Se a ideologia só existe através do sujeito, a questão passa a ser a definição de sujeito. Pode o sujeito ser mero objeto? Em francês, o sujeito pode ser o protagonista da ação, mas também o assunto de uma fala ou pesquisa. Logo, o objeto da observação. Excluída essa ambivalência, sujeito é aquele que tem subjetividade própria.

Se a ideologia tudo condiciona, tudo formata, como se viu, nada se dando fora do seu guarda-chuva, como é possível que alguém a perceba, compreenda, decifre e dela se liberte? Mais do que isso: pode um sujeito ser sujeito estando submetido a algo que ignora? Vale retomar alguns pontos. Se mesmo os cientistas, como diz Althusser (1989), "estão submetidos às ideologias correspondentes" (p. 49), como se explica que alguém pode quebrar a grade e livrar-se das ideias falsas que o mantêm na ignorância e na inversão da realidade? Se todos os fatos são recobertos por ideologias, como chegar aos fatos verdadeiros, que possam merecer o nome de emancipação, de liberdade e de autonomia? 
"Ensinemos os homens a trocar essas ilusões por pensamentos correspondentes à essência do homem, diz alguém", conforme a reflexão de Marx e Engels (1846/1998, p. 26). Como, porém, foi possível que esse alguém, assim como Marx e Engels, tenha podido perceber que estava sendo iludido? Debord (1997), na sua última tese, a de número 221, não admitia qualquer relativismo: "Emancipar-se das bases materiais da verdade invertida. Eis em que consiste a autoemancipação da nossa época. Essa 'missão histórica' de instaurar a verdade no mundo nem o indivíduo isolado nem a massa atomizada podem realizar" (p. 220). Só o proletariado como sujeito universal da história. Uma classe capaz de dissolver todas as classes e também a ideologia como inversão da verdade e encobrimento da realidade. Então, como se pode constatar, fica assentado que há verdade e realidade. Nem tudo é ideologia.

Como, no entanto, antes dessa dissolução, indivíduos isolados, como Marx e Engels (1846/1998) e Debord (1997), foram capazes de compreender essa dinâmica da ideologia e perceber a verdade por trás da falsificação? Pode uma classe deixar de ser classe depois da eliminação da classe a ela oposta? Pode um partido ainda ser partido quando não há mais parte, mas somente o partido único? Isso é verdade ou a persistência de ideologia? Como poderia haver parte quando só há o todo? Hall (2003, pp. 267-268) define ideologia como o referencial mental, o sistema de representação, que cada um usa para interpretar o funcionamento das sociedades. Trata-se de um software acoplado ao aparelho (organismo)? O sujeito tem autonomia para trocar o programa? Como pode conseguir essa autonomia se funciona a partir do programa? Se o programa lhe é imposto ao longo da vida de formação, o que pode fazer bugar o dispositivo?

Hall estaria dizendo que a ideologia são as ideias que orientam as ações e interpretações de indivíduos, classes e grupos? Isso não significaria um retorno ao idealismo? $\mathrm{Ou}$, se essas ideias derivam da materialidade dominante, como explicar que sejam abandonadas? A saída tradicional para esse impasse é o uso de uma categoria de abertura como a da autonomia relativa ou relativa autonomia (Poulantzas, 1977) do político em relação às estruturas. É o retorno, por outros caminhos, do "mais ou menos" concedido por Althusser $(1980,1989)$ em seu voo determinista. Como se dá, enfim, a tomada de consciência? Pode-se imaginar que alguém consciente desperte a consciência de outros. Como, porém, esse conscientizar tomou consciência da sua situação se também ele esteve submetido ao mesmo programa de inconsciência? A hipótese mais provável é que, como acontece na ciência, tudo parta de uma série de possibilidades: um insight (intuição), observação sistemática de experiências concretas, reflexão, discussão, comparação, análise. 
E se o elemento decisivo for a inteligência do observador? Se for a capacidade cerebral, por exemplo de um Karl Marx, o elemento a possibilitar a decifração do enigma e a descobrir o encoberto? A inteligência garante muito, mas não tudo. Por que dois gênios expostos a condições existenciais equivalentes chegam a conclusões opostas? Por que uma aposta na solução liberal e outro na marxista? Talvez a resposta seja a mesma de cientistas diante de problemas ainda não resolvidos, o que dá título a um livro de vulgarização da física: Não tenho a menor ideia (Cham \& Whiteson, 2019). Resposta simplória?

Não deixa de ser interessante constatar que a inteligência não figura como uma categoria séria, densa, respeitável, operacional, recorrente em debates sobre fenômenos complexos. Não ocorre a um intelectual explicar uma interpretação em função da inteligência do intérprete. Althusser, como bom estruturalista, buscou uma explicação para ideologia fora do sujeito com sua suposta subjetividade. Procurou na estrutura, ou seja, lá onde o sujeito é objeto. Caiu na armadilha de uma ideologia cientificista da objetividade externa ao observador?

A ideologia condiciona e limita, mas não condiciona nem limita a todos da mesma forma. Uns são mais vulneráveis do que outros. Ter informações não explica tudo. Adam Smith e Karl Marx eram bem-informados. O filtro ideológico, a lente que a ideologia impõe, pode distorcer a visão de muitos, mas não de todos. A visão de quem não se submete a uma dessas lentes pode, no entanto, vislumbrar panoramas diferentes dentro de uma mesma classe. Engels sugere um bom exemplo disso. Fatores não racionais parecem contar nas escolhas pretensamente racionais. A falta de informação pode, sem dúvida, como foi indicado, explicar grande parte da cegueira ideológica. Não tudo. Mesmo as estruturas mais rígidas sofrem infiltrações e revelam fissuras. A dengue é transmitida por um mosquito, não por uma formiga. Essa é uma verdade científica, não uma leitura condicionada por uma ideologia.

Em termos vulgares, ideologia, hoje, é o que impediria o outro de enxergar a realidade, a lente que cega em vez de ampliar o olhar. Ao mesmo tempo, autoideologia é a visão de mundo daquele que vê o que vê como vê e disso se orgulha. Entre categoria de acusação e profissão de fé, ideologia significa ver mal, ver pouco, não ver, deixar de ver, ou, no sentido oposto, ver com clareza tudo o que o outro não consegue ver. Em ciências humanas, mais do que nas ditas ciências duras, ainda é muito difícil dizer: não temos a menor ideia. Mais fácil é afirmar que só temos ideologia. Enxerga-se melhor a forma do que o formante, a limitação do que a liberdade, a estrutura do que a infiltração. Afinal, quem não vê é sempre esse outro que pode ser reduzido a objeto. $\overline{\mathrm{M}}$ 


\section{REFERÊNCIAS}

Althusser, L. (1980). Ideologia e aparelhos ideológicos do estado. Presença.

Althusser, L. (1989). A transformação da filosofia seguido de Marx e Lênin perante Hegel. Mandacaru, 1989.

Bourdieu, P., \& Passeron, J.-C. (1982). A reprodução. Francisco Alves.

Cham, J., \& Whiteson, D. (2019). Não tenho a menor ideia: Um guia para o universo desconhecido. BestSeller.

Chomsky, N. (2007, 8 de agosto). América rebelde: Uma entrevista com Noam Chomsky. Le Monde Diplomatique Brasil. https://bit.ly/3fiAXEW

de Tracy, D. (2013). Éléments d'idéologie : Idéologie proprement dite. Nabu Press. (Obra original publicada em 1804)

Debord, G. (1997). A sociedade do espetáculo. Contraponto.

Gramsci, A. (1979). Os intelectuais e a organização da cultura. Civilização Brasileira.

Hall, S. (2003). Da diáspora. Editora UFMG.

Kellner, D. (2001). A cultura da mídia: Estudos culturais: identidade e política entre o moderno e o pós-moderno. Edusc, 2001.

Marx, K., \& Engels, F. (1998). A ideologia alemã. Martins Fontes. (Obra original publicada em 1846)

Poulantzas, N. (1977). Poder político e classes sociais. Martins Fontes.

Stoppino, M. (1986). Ideologia. In N. Bobbio, N. Matteuci, \& G. Pasquino (Orgs.), Dicionário de Política (vol. 1, pp. 585-597). Editora UnB.

Zizek, S. (1996). O espectro da ideologia. In S. Zizek (Org.), Um mapa da ideologia (pp. 7-38). Contraponto.

Artigo recebido em 19 de dezembro de 2020 e aprovado em 7 de maio de 2021. 